\title{
Cytotoxicity of $p$-tyrosol and its derivatives may correlate with the inhibition of DNA replication initiation
}

\author{
EUN-YOUNG AHN ${ }^{1}$, YAHONG JIANG ${ }^{3}$, YANJUN ZHANG ${ }^{1}$, EUN MI SON ${ }^{1}$, SONG YOU $^{3}$, SHIN-WON KANG ${ }^{4,5}$, \\ JANG-SU PARK ${ }^{4}$, JEE H. JUNG ${ }^{6}$, BURM-JONG LEE ${ }^{1,2}$ and DONG-KYOO KIM ${ }^{1,2}$ \\ ${ }^{1}$ Biohealth Product Research Center; ${ }^{2}$ Department of Biomedicinal Chemistry and Institute of Functional Materials, \\ Inje University, Kimhae 621-749, Korea; ${ }^{3}$ School of Pharmaceutical Engineering, Shenyang Pharmaceutical University, \\ Shenyang 110016, P.R. China; ${ }^{4}$ Department of Chemistry and Centre for Innovative Bio-physio sensor Technology, \\ Pusan National University, Busan 609-735; ${ }^{5}$ Korea Basic Science Institute, Daejeon 305-333; \\ ${ }^{6}$ College of Pharmacy, Pusan National University, Busan 609-735, Korea
}

Received June 13,2007; Accepted July 19, 2007

\begin{abstract}
Tyrosol is a phenolic compound present in different dietary sources that can exert mild antioxidant properties based on in vitro and in vivo studies. In our study, two $p$-tyrosol derivatives ( $p$-tyrosyl gallate and $p$-tyrosyl acetate) were synthesized and compared together with $p$ tyrosol and gallic acid for their cytotoxic activities on human cancer cells. $p$-Tyrosyl gallate had the most potent cytotoxicity and the major cytotoxic mechanism of its action was studied. We found that in HeLa cells, $p$-tyrosyl gallate can effectively induce cell cycle arrest during $\mathrm{S}$ phase and inhibited in vitro simian virus (SV40 DNA) replication. In addition, $p$-tyrosyl gallate can inhibit three important functional replication proteins (topoisomerase I, RPA and pol $\alpha$-primase), especially pol $\alpha$-primase. These results suggest that $p$-tyrosyl gallate-induced cell cycle arrest during $\mathrm{S}$ phase correlates with the inhibition of DNA replication. Pol $\alpha$-primase may be the main target molecule. Taken together, we suggest that $p$-tyrosyl gallate is a strong anticancer drug candidate that warrants further investigation.
\end{abstract}

\section{Introduction}

Cell division is a central process in living organisms. This process culminates with the production of two daughter cells from one mother cell. Both cell growth and division are cell cycle dependent (1). Cell division is controlled by mechanisms that normally allow cells to divide only if and when new cells

Correspondence to: Dr Dong-Kyoo Kim, Department of Biomedicinal Chemistry, 607 Aubang-dong, Kimhae 621-749, Korea E-mail: chemkdg@inje.ac.kr

Key words: p-tyrosyl gallate, cell cycle, simian virus 40 DNA replication, RPA, topoisomerase I, pol $\alpha$-primase are required. Uncontrolled cell division is a feature of tumor growth. Before cell division can take place, a cell must double its mass and duplicate all its components. Most of these processes occur during the interphase period between cell divisions. Cellular DNA is replicated during the $\mathrm{S}$ phase of interphase (2). DNA replication is a tightly regulated progress in the cell cycle and requires the recruitment of multiple components such as the DNA polymerase $\alpha$-primase (pol $\alpha$ primase) complex, replication protein A (RPA), replication factor C (RFC), proliferating cell nuclear antigen (PANC) and topoisomerase I (topo I) (3). If DNA replication is blocked by an inhibitor or the DNA template is damaged by radiation or other factors, signals are generated that can induce cell-cycle arrest or apoptosis (4).

Much of what is currently known about the mechanism of DNA replication in eukaryotic cells has come from studying simian virus 40 (SV40) and related viruses (5). An in vitro SV40 DNA replication system was used extensively as a model to understand eukaryotic DNA replication and is used in anticancer drug analysis (6). SV40 is a small DNA tumor virus of the papovavirus family. SV40 can use the host replication machinery for its own DNA replication together with the sole viral protein, SV40 large tumor antigen (T-Ag). The latter is a multifunctional regulatory protein that binds to specific DNA sites at the replication origin to initiate replication with numerous biochemical activities (7). All other proteins during in vitro SV40 DNA replication are supplied by the host cell extracts. Ten cellular factors are sufficient to replicate SV40 DNA. Three of these, pol $\alpha$-primase, RPA and topo I, are necessary, together with $\mathrm{T}-\mathrm{Ag}$, for the initial replication stage $(3,5,8)$. RPA is a eukaryotic single-stranded DNA (ssDNA) binding protein that is involved in DNA replication, repair and recombination. During replication, RPA mediates the unwinding of SV40 origin-containing DNA in the presence of SV40 T-Ag and topo I. RPA interacts with T-Ag and the DNA pol $\alpha$-primase complex, an interaction that is necessary for the initiation of SV40 DNA replication (5). The pol $\alpha$-primase complex is responsible for the synthesis of the first DNA segment, which is considered the first lagging strand Okazaki fragment, but is then subsequently utilized as the primer for 
the initiation of leading strand synthesis by DNA pol $\delta(3)$. Topo I and II release the torsional stress on the DNA duplex that are caused by the progressing replication forks (8). By forming transient DNA single-strand breaks (referred to as 'cleavage complexes') and acting as DNA strand transferase, topo I plays key a role in DNA replication, transcription and recombination (9).

p-Tyrosol (4-Hydroxyphenethyl alcohol) is a well-known phenolic compound that is present in different dietary sources like virgin olive oil, wine and Rhodiola species (10). In fact, $p$-tyrosol is one of the major bioactive components in the Rhodiola species (11). In vitro and in vivo studies have shown that $p$-tyrosol exerts mild antioxidant properties (12).

Gallic acid (3,4,5-trihydroxybenzoic acid), which is naturally abundant in plants is also a well-known phenolic compound. In plants, this compound occurs as gallic acid and is a major product of the breakdown of gallotannins, which are the simple esters of gallic acid that are commonly produced by plants. Toxic effects of gallic acid have been demonstrated in rabbits, rats, sheep and brushtail possums (13). Gallic acid protects against oxidative damage induced by reactive oxygen species (ROS) (14) in order to cause apoptosis in some tumor cell lines (HL-60RG, HeLa, KB cells) with a higher sensitivity than normal cells $(15,16)$. Furthermore, some of these cells have an anti-thrombotic effect (17). In particular, the selectivity shown by gallic acid was independent of cell cycle progression, that is, gallic acid does not act at a specific phase of the cell cycle (15).

In this study, we synthesized two tyrosol derivative compounds, $p$-tyrosyl gallate and $p$-tyrosyl acetate. In our study, we showed that by correlating cell cycle arrest during $S$ phase with the inhibition of DNA replication, that $p$-tyrosyl gallate has a potent anticancer activity. Furthermore, we found that major inhibition of DNA replication by $p$-tyrosyl gallate treatment might be due to the inhibition of pol $\alpha$-primase activity.

\section{Materials and methods}

Synthesis of tyrosol derivatives. p-Tyrosol (hydroxyphenethyl alcohol) and gallic acid (3,4,5-trihydroxybenzoic acid) were purchased from Aldrich Chemical Company. All samples were dissolved in ethanol (EtOH) at a $100 \mathrm{mM}$ concentration and kept at $5^{\circ} \mathrm{C}$. The final concentration of EtOH in every assay did not exceed $1 \%$. Further dilutions to desired concentrations were made immediately prior to each experiment. All other chemicals were at an analytical reagent grade.

Infrared spectra were obtained on a Perkin-Elmer spectrometer using $\mathrm{KBr}$ plates. ${ }^{1} \mathrm{H}-\mathrm{NMR}$ spectra were recorded on a Bruker 300-MHz spectrometer. Chloroform-d and acetone- $\mathrm{d}_{6}$ were employed as deuterated solvents. Tetramethylsilane (TMS) was used as an internal standard. Silica gel 60 (Merck) was used for column chromatography.

p-Tyrosyl acetate (4-Hydroxyphenethyl acetate) (1). 4Hydoxyphenethyl alcohol $(0.02 \mathrm{~mol})$ was placed in a roundbottomed flask and mixed with ethyl acetate $(0.01 \mathrm{~mol})$ in the presence of $10 \mathrm{~mol} \%$-dodecylbenzenesulfonic acid (DBSA). The mixture was stirred for $24 \mathrm{~h}$ at $40^{\circ} \mathrm{C}$. The reaction mixture was then poured into water. After the organic layer was separated, it was dried with anhydrous magnesium sulfate. The solid was then filtered off. The filtrate was condensed on a rotary evaporator which resulted in a crude, dark yellow product. This crude product was chromatographed on silica gel using ethyl acetate and hexane as co-eluants. The fractions containing the product were condensed on a rotary evaporator to yield a light yellow solid. IR (KBr): $v=3400,3050,2980$, 1735, 1610, 1510, $1230 \mathrm{~cm}^{-1} .{ }^{1} \mathrm{H}-\mathrm{NMR}(\mathrm{CDCl} 3): \delta=2.08$ $(\mathrm{s}, 3 \mathrm{H}), 2.87(\mathrm{t}, 2 \mathrm{H}), 4.25(\mathrm{t}, 2 \mathrm{H}), 6.79(\mathrm{~d}, 2 \mathrm{H}), 7.18(\mathrm{~d}, 2 \mathrm{H})$. Calculated analysis for $\mathrm{C}_{10} \mathrm{H}_{12} \mathrm{O}_{2}: \mathrm{C}, 66.95 \% ; \mathrm{H}, 6.71 \%$; O, $26.64 \%$. Found: C, 66.35\%; H, 6.73\%; O, $25.77 \%$.

p-Tyrosyl gallate (4-Hydroxyphenethyl gallate) (2). A onenecked flask $(100 \mathrm{ml})$ was equipped with a calcium chloride tube and charged with $8.5 \mathrm{~g}(0.05 \mathrm{~mol})$ of gallic acid, $7.6 \mathrm{~g}$ $(0.055 \mathrm{~mol})$ of 4-hydroxyphenethyl alcohol and $30 \mathrm{ml}$ of dry tetrahydrofuran. The solution was stirred and cooled in an ice bath at $0^{\circ} \mathrm{C}$ while a dicyclohexylcarbodimide solution (DCC $11.35 \mathrm{~g}$ /dichloromethane $25 \mathrm{ml}$ ) was added over a $5 \mathrm{~min}$ period. After stirring at $0^{\circ} \mathrm{C}$ for 5 min more, the ice bath was removed and the dark orange reaction mixture was stirred for $3 \mathrm{~h}$ at room temperature. The dicyclohexylurea that precipitated from the mixture was removed by filtration. The filtrate was washed three times with water and $5 \%$ aq. acetic acid and then washed again only with water. The organic solution was dried over anhydrous magnesium sulfate and concentrated on a rotary evaporator. The crude product was chromatographed on silica gel using ethyl acetate and hexane as the eluants. The fractions containing the desired product were condensed on a rotary evaporator. The crude product was purified by recrystallization from the chloroform solution. IR $(\mathrm{KBr}): \mathrm{v}=3334,3050,2980,1687,1604,1456,1244 \mathrm{~cm}^{-1}$. ${ }^{1} \mathrm{H}-\mathrm{NMR}$ (acetone- $\mathrm{d}_{6}$ ): $\delta=2.98(\mathrm{t}, 2 \mathrm{H}), 4.39(\mathrm{t}, 2 \mathrm{H}), 6.8(\mathrm{~d}, 2 \mathrm{H})$, 7.15-7.35 (d, $4 \mathrm{H}), 8.19(\mathrm{~s}, 3 \mathrm{H})$. Calculated analysis for $\mathrm{C}_{15} \mathrm{H}_{14} \mathrm{O}_{6}$ : C, 62.07\%; H, 4.86\%; O, 33.07\%. Found: $\mathrm{C}$, $61.42 \%$; H, 5.340\%; O, 33\%.

Cell culture. The RPMI-1640 medium, fetal bovine serum (FBS) and $100 \%$ penicillin/streptomycin were from Hyclone Laboratories (Logan, UT). The Dulbecco's modified Eagle's medium (DMEM) containing high glucose was purchased from the Gibco-BRL (Gaithersburg, MD, USA). CCK-8 was purchased from Dojin Laboratories (Osaka, Japan). The human cancer cell lines HeLa (a cervical carcinoma), A549 (a lung carcinoma) and PANC-1 (a pancreatic carcinoma) were purchased from American Type Culture Collection (ATCC). Throughout all the experiments, the HeLa and PANC-1 cells were grown in DMEM while the A549 cells were grown in RPMI-1640. The media were supplemented with $10 \% \mathrm{FBS}$ and $1 \%$ penicillin/streptomycin. Cells were grown in $5 \% \mathrm{CO}_{2}$ humidified atmosphere at $37^{\circ} \mathrm{C}$. When the cultures reached $\sim 80 \%$ confluence, the cells were washed twice with PBS (pH 7.4) at $37^{\circ} \mathrm{C}$ and harvested by trypsinization. Fresh medium was added to prepare cell suspensions.

Measurement of cell viability. Cell suspensions $(5,000$ cells per well) were seeded in the 96-well plates (Nalgene Nunc International, Tokyo) and incubated for $24 \mathrm{~h}$ before treatment. The medium was then replaced with fresh medium containing 
various concentrations of tyrosol or its derivatives (from 100 to $800 \mu \mathrm{M})$. After $48 \mathrm{~h}$ incubation, a water-soluble tetrazolium salt-based cytotoxic assay (18) was performed to determine the number of surviving cells. This assay was performed by adding $10 \mu \mathrm{l}$ of the cell counting kit solution (CCK-8) to each well and then incubating the cells for $3 \mathrm{~h}$ at $37^{\circ} \mathrm{C}$. Dehydrogenase in living cells can convert 2-(2-methoxy-4nitrophenyl)-3-(4-nitrophenyl)-5-(2,4-disulfophenyl)-2Htetrazolium (WST-8) to formazan dye. The optical density of formazan dye for living cells was read at $450 \mathrm{~nm}$ in a multimicroplate reader (synergy HT, BIO-TEK ${ }^{\circledR}$ ).

DNA ploidy analysis. HeLa cells treated with $300 \mu \mathrm{M}$ of $p$ tyrosyl gallate $\left(0.8 \times 10^{6}\right.$ cells in each $60-\mathrm{mm}$ dish $)$ were collected by trypsinization at different time intervals and washed with cold PBS via centrifugation. The cells were suspended in PBS and fixed with $70 \%$ ethanol (v/v). Then, the cells were washed with PBS and stained with PI/RNase staining buffer (BD PharMingen) for $15 \mathrm{~min}$ at $4^{\circ} \mathrm{C}$. Data were acquired using CellQuest Software with a FACScalibur (Becton Dickinson) flow cytometry system using 20,000 cells per analysis. Cell cycle distributions were calculated using ModFit LT 2.0 software (verity Software House, Topsham, ME, USA).

Measurement of DNA replication in vivo. HeLa cells $\left(\sim 2 \times 10^{5}\right)$ were seeded in 6-well plates (Nalgene Nunc International, Tokyo) and incubated for $24 \mathrm{~h}$ to allow cell attachment to the plates. After attachment, DMEM supplemented with $10 \%$ FBS and various concentrations of the sample (or control) was added to the cells. After the cells were incubated for $24 \mathrm{~h}$, $\left[{ }^{3} \mathrm{H}\right] \mathrm{dTTP}$ was added at $1 \mu \mathrm{Ci} / \mathrm{ml}(1 \mu \mathrm{Ci}=37 \mathrm{kBq})$ and incubated with the cells for $3 \mathrm{~h}$. The cells in each well were harvested by trypsinization and washed with cold PBS. After centrifugation, the cell pellet was re-suspended in cold $5 \%$ TCA and incubated on ice for $30 \mathrm{~min}$. After washing with PBS, the $\left[{ }^{3} \mathrm{H}\right] \mathrm{dTTP}$ that had incorporated into nascent DNA was extracted with $0.5 \mathrm{ml}$ of cell lysis buffer (100 mM Tris$\mathrm{HCl}$; pH 8.0, 20 mM EDTA, 0.8\% SDS). The TCA-insoluble radioactivity was counted by measuring thymidine incorporation into DNA or DNA synthesis using a Tri-carb 2000CA liquid scintillation counter (Packard, Groningen, The Netherlands).

In vitro SV4O DNA replication assay. The reaction mixture (40 $\mu 1$ ) included $40 \mathrm{mM}$ creatine phosphate-di-Tris salt (pH 7.7), $1 \mu \mathrm{g}$ of creatine kinase, $7 \mathrm{mM} \mathrm{MgCl}_{2}, 0.5 \mathrm{mM}$ DTT, $4 \mathrm{mM}$ ATP, $200 \mu \mathrm{M}$ UTP, GTP and CTP, $100 \mu \mathrm{M}$ dATP, dGTP and dCTP, $25 \mu \mathrm{M}\left[{ }^{3} \mathrm{H}\right] \mathrm{dTTP}(300 \mathrm{cpm} / \mathrm{pmol})$,

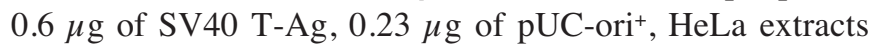
and each sample as indicated. The reactions were run at $37^{\circ} \mathrm{C}$ for $4 \mathrm{~h}$ and then measured for acid-insoluble radioactivity. In the previously described reactions, replication products were analyzed using $\left[\alpha^{-}{ }^{32} \mathrm{P}\right] \mathrm{dATP}(30000 \mathrm{cpm} / \mathrm{pmol})$ instead of $\left[{ }^{3} \mathrm{H}\right] \mathrm{dTTP}$. Replication products in the reaction mixture were analyzed by separating the isolated DNA by overnight electrophoresis on a $1.0 \%$ agarose gel at $42 \mathrm{~V}$. The gel was subsequently dried and analyzed with a Phosphor Image Analyzer (Typhoon 9400 Variable Mode Imager, Amersham Biosciences).
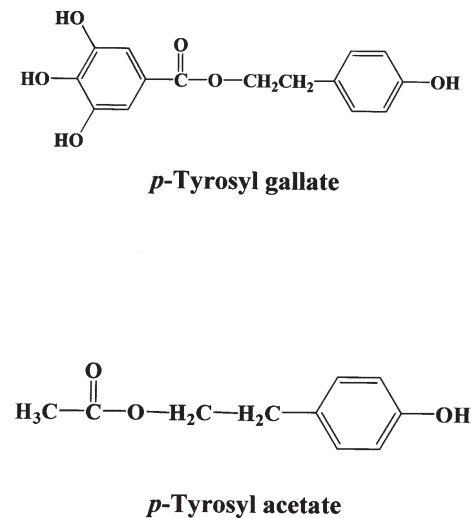

Figure 1 . The synthesized chemical structures of $p$-tyrosyl gallate and $p$-tyrosyl acetate.

Topoisomerase I assay. Topoisomerase I activity was measured by superhelical plasmid DNA relaxation. The $20 \mu 1$ of assay mixture contained $50 \mathrm{mM}$ Tris- $\mathrm{HCl}$ (pH 7.5), $120 \mathrm{mM}$ $\mathrm{KCl}, 10 \mathrm{mM} \mathrm{MgCl}_{2}, 0.5 \mathrm{mM}$ DTT, $0.5 \mathrm{mM}$ EDTA, BSA $(30 \mu \mathrm{g} / \mathrm{ml}), \mathrm{pBR} 322(20 \mu \mathrm{g} / \mathrm{ml})$, topo I and various sample concentrations. After $30 \mathrm{~min}$ at $30^{\circ} \mathrm{C}$, the reactions were stopped by the addition of $5 \mu \mathrm{l}$ of $5 \% \mathrm{NaDodSO}_{4} / 25 \%$ (wt/vol) Ficoll 400 (Pharmacia) containing $0.25 \mathrm{mg}$ of bromophenol blue per $\mathrm{ml}$. The reaction products were analyzed by electrophoresis and the results were photographed.

ssDNA binding assay. The reaction mixture $(20 \mu \mathrm{l})$ contained $50 \mathrm{mM}$ Hepes-KOH (pH 7.5), $150 \mathrm{mM} \mathrm{NaCl}, 1 \mathrm{mM} \mathrm{MgCl}$, $0.5 \mathrm{mM}$ DTT, $10 \%$ glycerol, 50 pmol of 5 '- ${ }^{32} \mathrm{P}$-labeled oligo $(\mathrm{dT})_{50}(2200 \mathrm{cpm} / \mathrm{pmol})$, plus RPA and was incubated for $15 \mathrm{~min}$ at room temperature. The complex was separated on a $5 \%$ polyacrylamide gel in $0.5 x \mathrm{TBE}(89 \mathrm{mM}$ Tris borate, $2 \mathrm{mM}$ EDTA) by electrophoresis at $15 \mathrm{~V} / \mathrm{cm}$. The gel was then dried and exposed to X-ray film.

DNA polymerase assay. The reaction mixtures $(30 \mu 1)$ contained $40 \mathrm{mM}$ creatine phosphate/di-Tris salt $(\mathrm{pH} 7.7)$, $1.0 \mu \mathrm{g}$ of creatine kinase, $7 \mathrm{mM} \mathrm{MgCl}, 1.0 \mathrm{mM}$ DTT, $6 \mu \mathrm{g}$ of bovine serum albumin, $4 \mathrm{mM}$ ATP, $33 \mu \mathrm{M}$ of $\left[{ }^{3} \mathrm{H}\right] \mathrm{dTTP}$ $(500 \mathrm{cpm} / \mathrm{pmol}), 0.1 \mu \mathrm{g}$ of poly $(\mathrm{dA})_{4500}$ : oligo $(\mathrm{dT})_{25}(20: 1)$, DNA pol $\alpha$ and one of the samples. After incubation at $37^{\circ} \mathrm{C}$ for $30 \mathrm{~min}$, the acid-insoluble radioactivity of each sample was determined.

\section{Results}

The effects of tyrosol and its derivatives on human cancer cell cytotoxicity. The structure of p-tyrosyl acetate and p-tyrosyl gallate are shown in Fig. 1. To investigate the effects of tyrosol and its derivatives on the cytotoxicity, a cell viability assay using CCK-8 was carried out with three different human cancer cells, which included the HeLa (a cervical carcinoma), A549 (a lung carcinoma) and PANC-1 (a pancreatic carcinoma) cell lines. The $48 \mathrm{~h}$ treatment with $p$ tyrosyl gallate reduced the cell viability of all three cancer cell types more than the other compounds. Furthermore, the pancreatic carcinoma cell line, PANC-1, showed the most sensitivity. The results indicate that $p$-tyrosyl gallate had the 
(A)

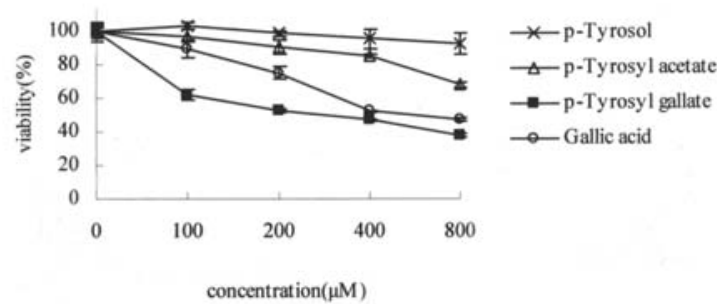

(B)

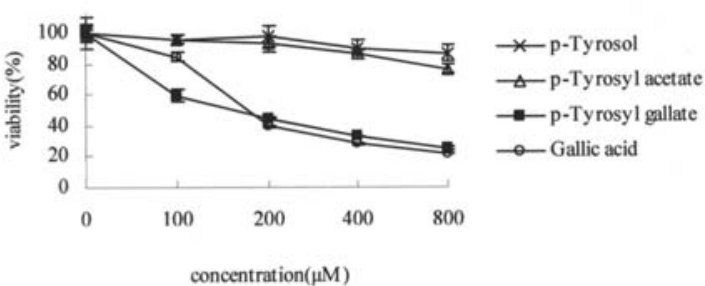

(C)

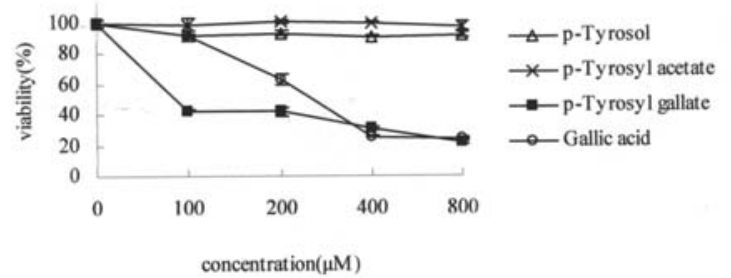

Figure 2. The effects of $p$-tyrosol, $p$-tyrosyl acetate, $p$-tyrosyl gallate and gallic acid on the viability of several cell lines (HeLa (A), A549 (B) and PANC-1 (C). All cells were treated with various concentrations of the compounds for $48 \mathrm{~h}$. Relative cell viability was determined by WST- 8 and is shown as a percentage of living cells over the control (100\%). Data are shown as means $\pm \mathrm{SD}$ of three independent experiments.

most potent cytotoxicity and that $p$-tyrosyl acetate did not have a significant cytotoxicity compared to the $p$-tyrosyl gallate (Fig. 2). As shown in Fig. 2, the general trend of increasing cytotoxicity was $p$-tyrosol $<p$-tyrosyl acetate $<$ gallic acid $<p$-tyrosyl gallate.

Effect of p-tyrosyl gallate on the cell cycle distribution. To investigate the strong cytotoxic effect of the cell cycle perturbation induced by $p$-tyrosyl gallate, we performed a flow cytometric analysis of propidium iodide stained nuclei. When we examined the effect of $p$-tyrosol, $p$-tyrosyl acetate and gallic acid on cells, the distribution of HeLa cells was not significantly affected (data not shown). Since the $\mathrm{IC}_{50}$ value of $p$-tyrosyl gallate was $\sim 300 \mu \mathrm{M}$ for HeLa cells (Fig. 2A), HeLa cells were treated with this inhibitor concentration for various time periods $(12,36,24,48$ and 60 h). As shown in Fig. 3, flow cytometric analysis indicated that $p$-tyrosyl gallate could time-dependently perturb the $\mathrm{S}$ phase. After $60 \mathrm{~h}$ of treatment, the population of HeLa cells in the $\mathrm{S}$ phase significantly increased from 27.86 to $55.15 \%$. This increase consequently occurred when the G2/M cell population decreased from 20.61 to $0.62 \%$. Therefore, this

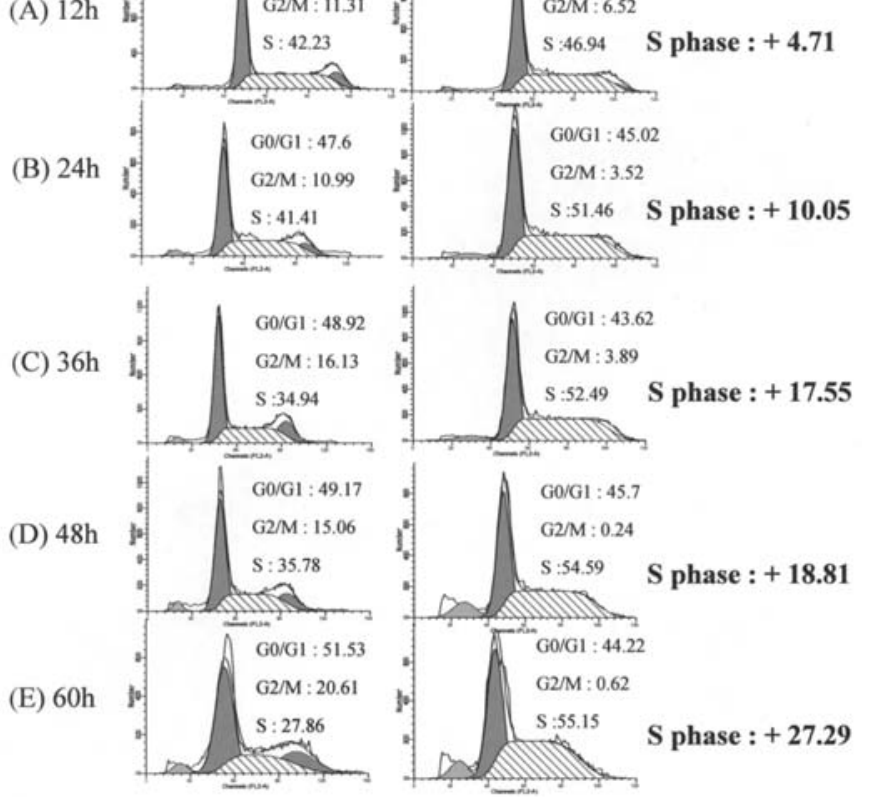

Figure 3. The analysis of cellular DNA content by the effect of $p$-tyrosyl gallate on cell cycle progression in HeLa cells. HeLa cells were treated with $300 \mu \mathrm{M} p$-tyrosyl gallate for $12 \mathrm{~h}$ (A), $24 \mathrm{~h}$ (B), $36 \mathrm{~h}$ (C), $48 \mathrm{~h}$ (D) $60 \mathrm{~h}$ (E). The control was added to the medium without sample. DNA content was analyzed by flow cytometry with PI staining. The cell cycle distribution was calculated as the percentage of cells containing G0/G1, S and G2/M phase. Data are analyzed with 20,000 counted cells and representative of five independent experiments.

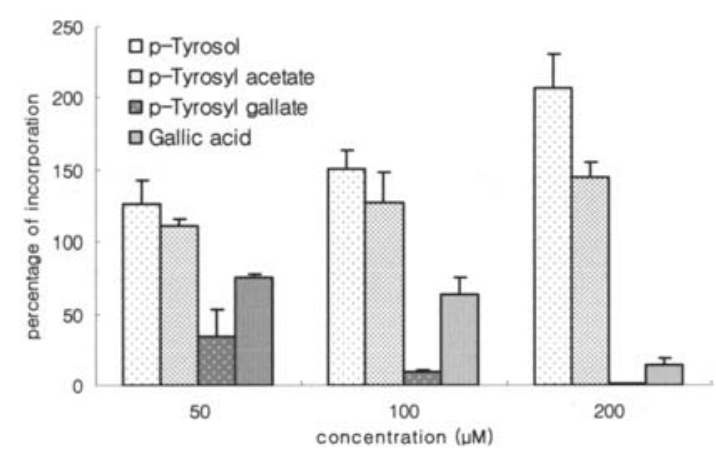

Figure 4. Effect of $p$-tyrosol, $p$-tyrosyl acetate, $p$-tyrosyl gallate and gallic acid on DNA replication in HeLa cells. The HeLa cells were treated with various concentrations of compounds for $24 \mathrm{~h}$ before $1 \mu \mathrm{Ci} / \mathrm{ml}$ of $\left[{ }^{3} \mathrm{H}\right]$ thymidine was added. DNA synthesis was measured by $\left[{ }^{3} \mathrm{H}\right]$ thymidine incorporation into nascent DNA and was expressed as the relative percentage value from the control $(100 \%)$. Each bar indicates the mean \pm SD value of three independent experiments.

result indicates that $p$-tyrosyl gallate blocked cell cycle progression in HeLa cells during the $\mathrm{S}$ phase because HeLa cells did not enter into the G2/M phase.

Effect of tyrosol and its derivatives on the DNA synthesis in HeLa cells. In order to clarify the mechanism of action for the $\mathrm{S}$ phase arrest in HeLa cells, we examined the effect of tyrosol and its derivatives on DNA synthesis by measuring labeled thymidine incorporation into nascent DNA. As 
A

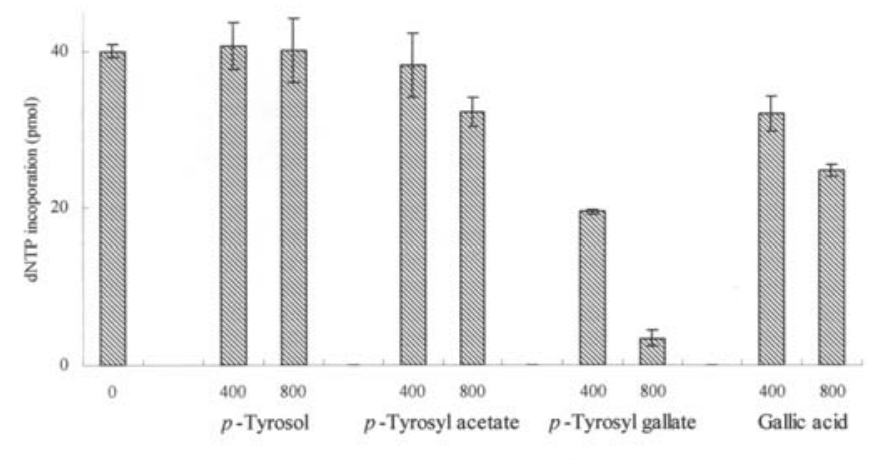

concentration $(\mu \mathrm{M})$

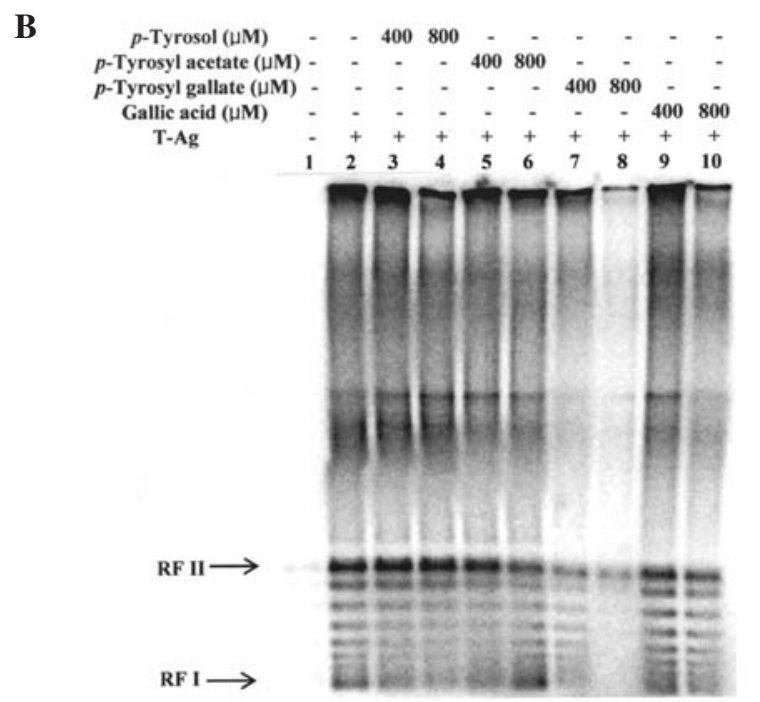

Figure 5. The effect of tyrosol and its derivatives on SV40 DNA replication in vitro. The replication reaction was comprised of SV40 origin-containing DNA (pUC-ori ${ }^{+}$), SV40 T-Ag, HeLa cytosolic extract $(100 \mu \mathrm{g}),\left[{ }^{3} \mathrm{H}\right] \mathrm{dTTP}$, and the indicated amounts of compound. Reaction mixtures were incubated for $4 \mathrm{~h}$ at $37^{\circ} \mathrm{C}$ and the reaction products were examined for acid-insoluble radioactivity (A) and then separated by $1 \%$ agarose gel electrophoresis (B). Each data point is the mean \pm SD of three independent experiments.

shown in Fig. 4, although $p$-tyrosol was synergetic to DNA synthesis, $p$-tyrosyl gallate had a strong inhibition of DNA synthesis in HeLa cells. In fact, $200 \mu \mathrm{M}$ of $p$-tyrosyl gallate completely inhibited DNA synthesis. In contrast, $p$-tyrosyl acetate did not show any significant effect (Fig. 4). The general trend of inhibition upon DNA synthesis in HeLa cells was: $p$-tyrosol $<p$-tyrosyl acetate $<$ gallic acid $<p$-tyrosyl gallate. The same general trend was observed when measuring increased cytotoxicity.

Effect of tyrosol and its derivatives on the SV4O DNA replication in vitro. Figs. 3 and 4 show that the $S$ phase arrest and the strong inhibition of DNA synthesis in HeLa cells were induced by $p$-tyrosyl gallate. Consequently, by using an SV40 DNA replication system in vitro, we confirmed that $p$-tyrosyl gallate could inhibit DNA replication. This in vitro SV40 DNA replication was performed using HeLa cell extracts. Every compound except $p$-tyrosol inhibited DNA replication (Fig. 5A). p-tyrosyl gallate had the strongest inhibition and is
A

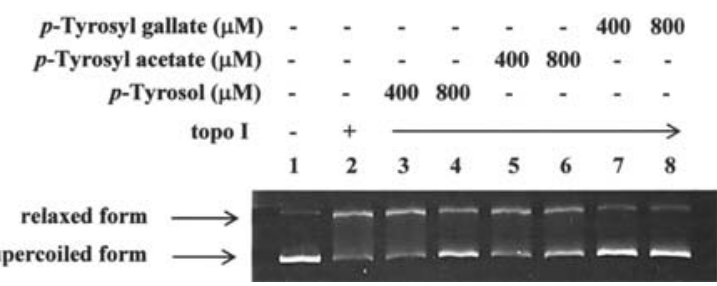

B

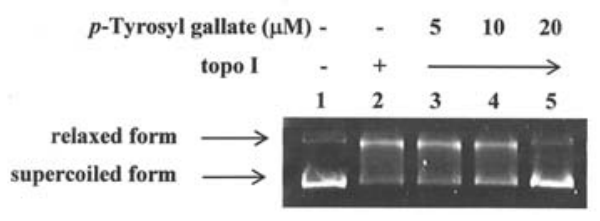

C

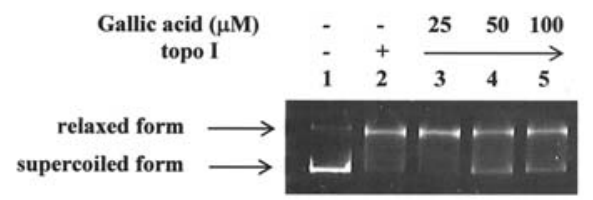

Figure 6. Inhibition of topoisomerase I catalytic activity by $p$-tyrosol, $p$ tyrosyl acetate and p-tyrosyl gallate (A), p-Tyrosyl gallate (B) and gallic acid (C). Topoisomerase was measured by the relaxation of superhelical plasmid DNA. The assay mixture $(20 \mu \mathrm{l})$ contained pBR322 $(20 \mu \mathrm{g} / \mathrm{ml})$, topoisomerase I and the indicated concentrations of compound. After $30 \mathrm{~min}$ at $30^{\circ} \mathrm{C}$, the reaction was stopped by the addition of $5 \mu 1$ of stop solution. The samples were loaded onto the agarose gel $(0.8 \%)$ for electrophoresis and then photographed.

indicated in Fig. 4 as having the strongest inhibitory effect on DNA synthesis. The inhibitory activity of $p$-tyrosyl gallate was 52 and $92 \%$ at 400 and $800 \mu \mathrm{M}$ concentrations, respectively (Fig. 4A). Natural agarose gel electrophoresis showed that the replication products included RF I, RF II (circular duplex DNA containing at least one single-strand break), intervenient topoisomers and discrete slowermigrating species (Fig. 5B). As depicted in Fig. 5B, the replication product analysis showed that $p$-tyrosyl gallate severely inhibited the synthesis of all forms of DNA (lane 7 and 8 ). This result suggests a functional interference of the complex that carries out DNA replication. The general trend for increased DNA replication inhibition was p-tyrosol $<p$ tyrosyl acetate $<$ gallic acid $<p$-tyrosyl gallate. This trend was identical when assessing the increased inhibitory effect on DNA synthesis in HeLa cells.

The effect of tyrosol and its derivatives on the activity of topo I-mediated DNA relaxation. Since we found that $p$ tyrosyl gallate can inhibit DNA replication, we wanted to determine the possible $p$-tyrosyl gallate target molecules in DNA replication. In this study, we checked the effects on three important replication proteins: topo I, RPA and pol $\alpha$ primase. We asked whether $p$-tyrosol and its derivatives could inhibit topo I activity, an activity that is key to the processes of DNA replication, transcription and recombination through the ability of topo I to form transient DNA single-strand breaks and act as a DNA strand transferase (9). The inhibitory effects of these compounds on the catalytic activity of topo I are shown in Fig. 6A, B and C. Lane 1 shows the plasmid DNA in the supercoiled form, while in lane 2 topo I induced the relaxed form of the plasmid. $p$-Tyrosol, $p$-tyrosyl acetate 
A
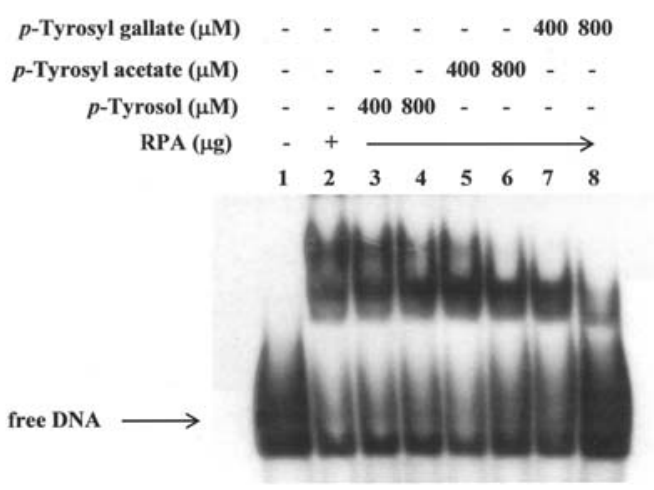

B

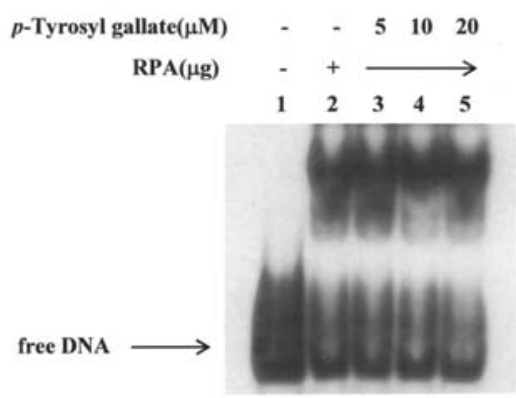

C

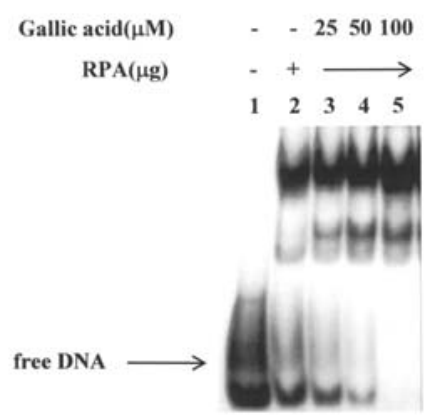

Figure 7. The effect of $p$-tyrosol, $p$-tyrosyl acetate and $p$-tyrosyl gallate (A), p-tyrosyl gallate (B), and gallic acid (C) on the ssDNA binding activity of RPA. A mixture of RPA and the indicated concentrations of the compound was combined with ${ }^{32} \mathrm{P}$-labeled $(\mathrm{dT})_{50}$ and incubated at $25^{\circ} \mathrm{C}$ for $15 \mathrm{~min}$. The protein-DNA complexes were then separated from unbound DNA by $5 \%$ polyacrylamide (acrylamide : bisacrylamide $=29: 1$ ) gel electrophoresis .

and $p$-tyrosyl gallate inhibited topo I-induced DNA cleavage (Fig. 6A). Among these compounds, $p$-tyrosyl gallate completely reduced this relaxation with both treatment concentrations (400 and $800 \mu \mathrm{M}$, lane 7 and 8 , respectively in Fig. 6A). In order to determine the appropriate inhibition concentration, the $p$-tyrosyl gallate and gallic acid were titrated. $p$-tyrosyl gallate $(10 \mu \mathrm{M})$ can inhibit the topo I activity (lane 4 in Fig. 6B), but $25 \mu \mathrm{M}$ of gallic acid could not inhibit this activity (lane 4 in Fig. 6C). Figs. 6A, B and C indicate that $p$-tyrosyl gallate had the strongest inhibitory activity on topo I. About $20 \mu \mathrm{M}$ of $p$-tyrosyl gallate can entirely inhibit topo I activity.

The effect of tyrosol and its derivatives on the single-strand DNA-binding activity of RPA. RPA is a single-strand DNA binding protein that plays a pivotal role in DNA replication, repair and homologous recombination. In addition to DNA binding, the function of RPA is to orchestrate the specific interactions of nuclear proteins (19). Therefore, we asked
A

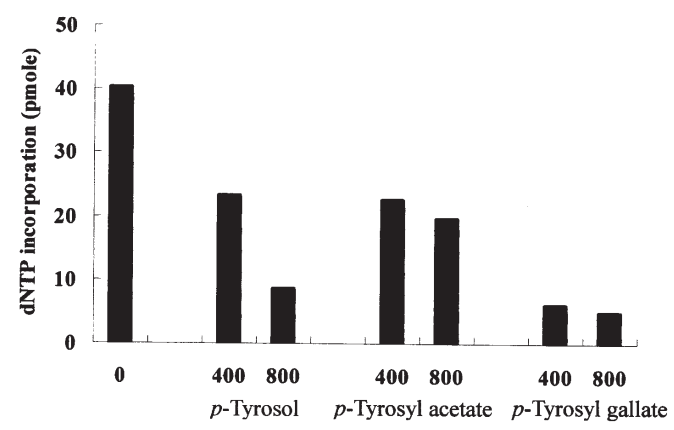

Concentration $(\mu \mathrm{M})$

$\mathbf{B}$

60

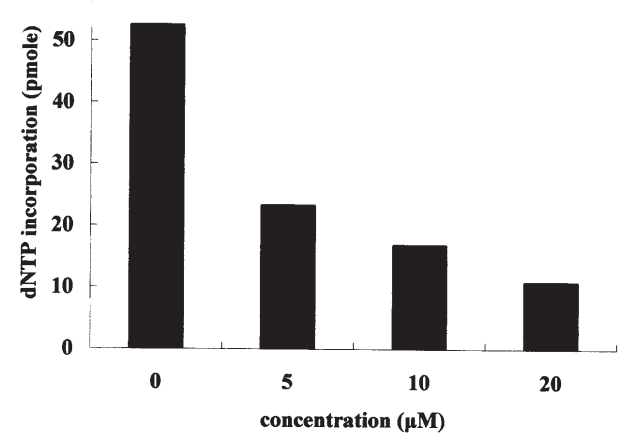

C

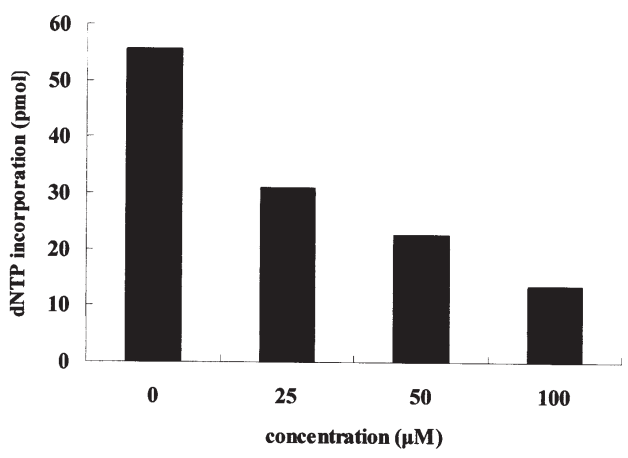

Figure 8 . The effect of $p$-tyrosol, $p$-tyrosyl acetate and $p$-tyrosyl gallate (A), $p$-tyrosyl gallate (B) and gallic acid (C) on pol $\alpha$-primase activity. The indicated concentrations of compounds were added to the reaction mixture, which included 0.1 units of human pol $\alpha$-primase complex, $4.0 \mathrm{mM} \mathrm{ATP,}$ $1.0 \mathrm{mM}\left[{ }^{3} \mathrm{H}\right] \mathrm{dTTP}$ and $0.1 \mu \mathrm{g}$ of poly $(\mathrm{dA})_{4500}: \operatorname{oligo}(\mathrm{dT})_{25}(20: 1)$. The incubation ran at $37^{\circ} \mathrm{C}$ for $30 \mathrm{~min}$ and was followed by a measurement of acid-insoluble radioactivity.

whether tyrosol and its derivatives can inhibit the ssDNA binding activity of RPA, which is an important protein for replication inhibition. As shown in Fig. 7A, B and C, RPA formed stable complexes with oligo $(\mathrm{dT})_{50}$, which appeared as distinct bands in the polyacrylamide gel (lane 2). $p$-Tyrosol, $p$-tyrosyl acetate and $p$-tyrosyl gallate can inhibit the ssDNA binding activity of RPA. $p$-Tyrosyl gallate showed the strongest inhibition of all the treatments (Fig. 7A). When $p$ tyrosyl gallate was titrated with the same concentrations used in Fig. 6B $(5,10$, and $20 \mu \mathrm{M})$, p-tyrosyl gallate did not show any inhibitory effect in this concentration range (Fig. 7B). When we examined the effects of gallic acid using the same concentrations as in Fig. 6C (25, 50 and $100 \mu \mathrm{M})$ we found that gallic acid did not have an inhibitory but instead had a stimulatory effect on the ssDNA binding assay with RPA (Fig. 7C). Based on the results of Fig 7A, B and C we can 
suggest that $p$-tyrosyl gallate can synergically have a strong inhibition in ssDNA binding activity of RPA by combining of $p$-tyrosol which has a very weak inhibitory effect and gallic acid which has a stimulatory effect. Furthermore, RPA is not the main target involved in $p$-tyrosyl gallate-induced replication inhibition.

The effect of tyrosol and its derivatives on the activity of DNA pol $\alpha$-primase. Pol $\alpha$-primase is the only enzyme capable of initiating de novo DNA synthesis by first synthesizing an RNA primer and then extending the primer by polymerization to produce a short extension (3). Based on this consideration, we examined the inhibitory effect of pol $\alpha$-primase activity by tyrosol and its derivatives. As shown in Fig. 8A, the activity of pol $\alpha$-primase was inhibited by these compounds. In particular, $p$-tyrosyl gallate strongly inhibited pol $\alpha$-primase activity. Fig. 8B shows that $5 \mu \mathrm{M}$ of $p$-tyrosyl gallate reduced the pol $\alpha$-primase activity $>50 \%$. Fig. $8 \mathrm{C}$ shows that $25 \mu \mathrm{M}$ of gallic acid reduced pol $\alpha$-primase activity to $<50 \%$. Fig. 8A, B and C indicate that p-tyrosyl gallate had the strongest inhibitory activity on pol $\alpha$-primase and that pol $\alpha$-primase might be the main target protein involved in $p$ tyrosyl gallate-induced inhibition of DNA replication.

\section{Discussion}

p-Tyrosol, which has one phenolic hydroxyl group and gallic acid, which has three phenolic hydroxyl groups, are well known mono-phenols. The antioxidant activity of $p$-tyrosol and gallic acid have been extensively investigated and well documented for their mild and strong antioxidant activity, respectively $(12,14)$. In this study, we found that $p$-tyrosyl gallate, which is synthesized via esterification of $p$-tyrosol and gallic acid, has a potent anticancer activity. Even though the synthesized $p$-tyrosyl acetate showed little cytotoxicity on HeLa cells, we did not find a specific cell cycle arrest in HeLa cells (data not shown) nor significant effects in any of the results. As shown in Fig. 2, de novo synthesized $p$-tyrosyl gallate was the strongest cytotoxic compound in the three cancer cell lines (HeLa, A549 and PANC-1). We studied the cytotoxic activity induced by $p$-tyrosyl gallate in order to clarify the major mechanism of cytotoxic action in HeLa cells. We also investigated $p$-tyrosyl and $p$-tyrosyl derivativeinduced inhibition of DNA replication and the potential effects on three important replication-associated proteins, topoisomerase, RPA and pol $\alpha$-primase. Replication inhibition can be mediated either by damaging the template DNA or by modulating the activity of one or more proteins required for DNA replication. The hypothesis that the anticancer activity of p-tyrosyl gallate might be mediated by a damaged template was demonstrated by an analysis of DNA replication products (Fig. 5B). Usually the replication products of a damaged template show relatively greater amounts of nicked and linear DNA (20). In contrast, $p$-tyrosyl gallate inhibited the synthesis of all DNA forms (lane 7 and 8 in Fig. 5B), suggesting a functional interference of the DNA replication complex. As shown above, $p$-tyrosyl gallate, which blocked the DNA synthesis, can also inhibit DNA replication. This inhibition by $p$-tyrosyl gallate can be induced by the inhibition of DNA replication-associated proteins, especially pol $\alpha$-primase. We discovered that gallic acid has a stimulating effect on the ssDNA binding activity of RPA in contrast to the inhibitory effect of topo I and pol $\alpha$-primase. However, after synthesis with $p$-tyrosol, $p$-tyrosyl gallate synergically showed a stronger inhibitory effect on the ssDNA binding activity of RPA when compared to other compounds. These biological activities of $p$-tyrosyl gallate might be explained by i) the synergistic effect of the gallic and $p$-tyrosol combination, ii) the increasing number of phenolic hydroxyl groups and iii) the increasing hydro-phobicity of $p$-tyrosyl gallate due to the addition of one more phenyl group. In previous years, structure-activity relationship studies have suggested that phenolic compounds with two or more phenolic hydroxyl groups may inhibit biological activities (21). These studies have demonstrated that the recognized cytotoxic activity of phenolic derivatives depend on their rate of incorporation into cells, which is directly related to their hydrophobicity as much as to their antioxidant activity. Both of these properties are affected by the presence of the phenolic substituent hydroxyl groups and in poly-hydroxylated phenolic esters, by the length of the ester moiety (22). In our study, $p$-tyrosyl gallate had an increased number of phenolic hydroxyl groups and an increased hydrophobicity via the synthesis of $p$ tyrosol and gallic acid. Furthermore, $p$-tyrosyl gallate showed stronger anticancer activity. In conclusion, $p$-tyrosyl gallate, which demonstrates a potent anticancer activity by arresting cell cycle progression via the inhibition of DNA replication, warrants further investigation as a chemotherapeutic anticancer agent. We hope our findings will provide useful information for the development of new and more efficient anticancer drugs that are structurally based on phenolic compounds.

\section{Acknowledgements}

This study was supported by a grant from the Korea Institute of Industrial Technology Evaluation \& Planning (ITEP) through the Biohealth Products Research Center (BPRC) of Inje University.

\section{References}

1. Nurse P: Ordering S phase and M phase in the cell cycle. Cell 79: 547-550, 1994.

2. DeVita Jr VT, Hellman S and Rosenberg SA: Cancer: Principles and Practice of Oncology, 5th ed. PA, Philadelphia, pp58-64, 1997.

3. Waga S and Stillman B: The DNA replication fork in eukaryotic cells. Annu Rev Biochem 67: 721-751, 1998.

4. Pizer ES, Chrest FJ, Digiuseppe JA and Han WF: Pharmacological inhibitors of mammalian fatty acid synthase suppress DNA replication and induce apoptosis in tumor cell line. Cancer Res 58: 4611-4615, 1998.

5. Hurwitz J, Dean FB and Kwong AD: Minireview: The in vitro replication of DNA containing the SV40 origin. J Biol Chem 265: 18043-18046, 1990

6. Snapka RM, Ferrer CA and Sun NJ: The SV40 replicon model for analysis of anticancer drugs: In drug discovery and evaluation with SV40. (Snapka RM ed). Academic Press, London, pp127-148, 1996.

7. Ott RD, Wang $\mathrm{Y}$ and Fanning E: Mutational analysis of simian virus $40 \mathrm{~T}$-antigen primosome activities in viral DNA replication. J Virol 76: 5121-5130, 2002.

8. Waga S, Bauer G and Stillman B: Reconstitution of complete SV40 DNA replication with purified replication factors. J Biol Chem 269: 10923-10934, 1994. 
9. Pommier Y, Kohlhagen G, Wu C and Simmons DT: Mammalian DNA topoisomerase I activity and poisoning by campothesin are inhibited by simian virus 40 large $\mathrm{T}$ antigen. Biochemistry 37: 3818-3823, 1998.

10. Cui S, Hu X and Chen X: Determination of p-tyrosol and salidroside in three samples of Rhodiola crenulata and one of Rhodiola kirilowii by capillary zone electrophoresis. Anal Bioanal Chem 377: 370-374, 2003.

11. Casas EM, Albadalejo MF and Planells MIC: Tyrosol bioavailability in humans after ingestion of virgin olive oil. Clin Chem 47: 341-343, 2001.

12. Covas MI, Miro-Casas E, Fito M, Farre-Albadalejo M, Gimeno E and Marrugat J: Bioavailability of tyrosol, an antioxidant phenolic compound present in wine and olive oil, in humans. Drugs Exp Clin 29: 203-206, 2003.

13. Wiggins NL, McArthur C and McLean S: Effects of two plant secondary metabolites, cineole and gallic acid, on nightly feeding patterns of the common brushtail possum. J Chem Ecol 29: 1447-1464, 2003.

14. Polewski K, Kniat S and Slawinska D: Gallic acid, a nature antioxidant, in aqueous and micellar environment: spectroscopic studies. Curr Top Biophys 26: 217-227, 2002.

15. Inoue M, Suzuki R and Koide T: Antioxidant, gallic acid, induces apoptosis in HL-60RG cells. Biochem Biophys Res Commun 204: 898-904, 2002.
16. Inoue M, Suzuki R and Sakaguchi N: Selective induction of cell death in cancer cells by gallic acid. Bio Pharm Bull 18: 1526-1530, 1995.

17. Yun HS, Kang SS and Kim HM: Anti-thrombotic effects of analogs of protocatechuic acid and gallic acid. Yakhak Hoeji 37: 453-457, 1993

18. Tominaga H, Ishiyama $\mathrm{M}$ and Ohseto F: Water-soluble tetrazolium salt useful for colorimetric cell viability assay. Anal Commun 36: 47-50, 1999.

19. Bae SH, Bae KH, Kim JA and Seo YS: RPA governs endonuclease switching during processing of Okazaki fragment in eukaryotes. Nature 412: 456-461, 2001.

20. McGregor WG, Wei D, Maher VM and McCormick JJ: Abnormal: error-prone bypass of photoproducts by xeroderma pigmentosum variant cell extracts results in extreme strand bias for the kinds of mutations induced by UV light. Mol Cell Biol 19: 147-154, 1999.

21. Gomes CA, Cruz TG, Andrade JL, et al: Anticancer activity of phenolic acids of natural or synthetic origin: a structure-activity study. J Med Chem 46: 5395-5401, 2003.

22. Fiuza SM, Gomes C, Teixeira LJ, et al: Phenolic acid derivatives with potential anticancer properties a structure-activity relationship study. Part 1: Methyl, propyl and octyl esters of caffeic and gallic acid. Bioorg Med Chem 12: 3581-3589, 2004. 